\title{
A JURISDIÇÃO DA CORTE INTERAMERICANA DE DIREITOS HUMANOS SOBRE O DIREITO AO MEIO AMBIENTE SAUDÁVEL
}

\section{THE JURISDICTION OF THE INTER-AMERICAN COURT OF HUMAN RIGHTS OVER THE RIGHT TO A HEALTHY ENVIRONMENT}

\author{
LUCAS CARLOS LIMA \\ Universidade Federal de Minas Gerais \\ Iclima@ufmg.br
}

Fecha de recepción: 18 de marzo de 2021 / Fecha de aceptación: 16 de abril de 2021

RESUMO: O presente artigo explora desenvolvimentos recentes em relação à proteção do meio ambiente na jurisprudência da Corte Interamericana de Direitos Humanos, especialmente no que diz respeito à Opinião Consultiva 23/17 e ao caso Lhaka Honhat. Seu objetivo é identificar as técnicas utilizadas pela CIDH a fim de expandir seu alcance em relação à proteção do direito a um meio ambiente saudável. Metodologicamente, são analisadas as decisões da Corte, tanto em sede consultiva quanto contenciosa, bem como a literatura existente sobre o tema e as principais reações sobre as decisões analisadas. Argumenta-se que, ao passo que a jurisprudência ambiental recente cristaliza progresso importante na proteção de direitos ambientais no Sistema Interamericano, há possíveis problemas com a proteção do direito autônomo a um meio ambiente saudável sob o artigo 26 da Convenção. Conclui-se explorando os desdobramentos dos argumentos adotados pela CIDH no que tange à sua função consultiva, e o criticismo à abordagem da Corte sobre questões ambientais recebidos de alguns juízes. 
RESUM: L'article explora els progressos recents quant a la protecció del medi ambient en la jurisprudència de la Cort Interamericana de Drets Humans i, en concret, en atenció a l'Opinió Consultiva 23/17i el cas Lhaka Honhat. El propòsit de l'article, per tant, és identificar les tècniques emprades per la Cort IDH per expandir l'abast de la seva protecció del dret a un medi ambient sa. Des d'una perspectiva metodològica, vaig analitzar les decisions de la Cort, tant en la seva jurisdicció consultiva com contenciosa, així com la literatura existent sobre el tema i les reaccions principals a les decisions analitzades. Argumento que, si bé la jurisprudència ambiental recent cristal-litza un progrés important en la protecció dels drets mediambientals en el Sistema Interamericà, encara existeixen problemes potencials relacionats amb la protecció del dret autònom a un medi ambient sa amb base en l'Article 26 de la Convenció. Concloc explorant tant les conseqüències dels arguments sobre els quals la Cort IDH s'ha pronunciat en l'exercici de la seva funció consultiva, com les crítiques d'alguns jutges a l'enfocament amb el qual la Cort aborda els assumptes mediambientals.

RESUMEN: El artículo explora los desarrollos recientes en relación a la protección del Medio Ambiente en la jurisprudencia de la Corte Interamericana de Derechos Humanos, especialmente en lo que respecta a la Opinión Consultiva 23/17 y al caso Lhaka Honhat. Su objetivo es identificar las técnicas empleadas por la Corte IDH para ampliar su alcance en relación con la protección del derecho a un medio ambiente sano. Metodológicamente, analizo las decisiones de la Corte, ya sea en su jurisdicción consultiva o contenciosa, así como la literatura existente sobre el tema y las principales reacciones sobre las decisiones analizadas. Argumento que, si bien la reciente jurisprudencia ambiental cristaliza importantes avances en la protección de los derechos ambientales en el Sistema Interamericano, existen potenciales problemas en la protección del derecho autónomo a un medio ambiente sano bajo el artículo 26 de la Convención. Concluyo explorando las consecuencias del desarrollo de los argumentos adoptados por la Corte IDH en relación con su función consultiva, y las críticas al enfoque de la Corte en materia ambiental recibidas por parte de algunos jueces. 
ABSTRACT: The article explores recent developments in relation to the protection of the Environment in the case law of the Inter-American Court of Human Rights, especially with regard to the Advisory Opinion 23/17 and the Lhaka Honhat case. Its purpose is to identify the techniques employed by the IACtHR in order to expand its reach in relation to the protection of the right to a healthy environment. Methodologically, I analyzed the decisions of the Court, either on its advisory or contentious jurisdiction, as well as the existing literature on the subject and the main reactions on the analyzed decisions. I argue that, while the recent environmental case law crystallizes important progress in the protection of environmental rights in the Inter-American System, there are potential problems with the protection of the autonomous right to a healthy environment under Article 26 of the Convention. I conclude by exploring the unfolding consequences of the arguments adopted by the IACtHR in relation to its advisory function, and the criticism of the Court's approach to environmental matters received from some judges.

PALAVRAS-CHAVE: Corte Interamericana - Direito Internacional Ambiental Direitos Humanos.

PARAULES CLAU: Cort Interamericana de Drets Humans - Dret Internacional del Medi Ambient - Drets Humans.

PALABRAS CLAVE: Corte Interamericana de Derechos Humanos - Derecho internacional del Medio Ambiente - Derechos Humanos.

KEY WORDS: Inter-American Court of Human Rights - International Environmental Law - Human Rights.

SUMÁRIO: Introdução. 1. A contribuição da opinião consultiva ํo 23 sobre meio ambiente e direitos humanos para o direito interamericano de direitos humanos. 2. Expandindo o escopo da questão: conectando o meio ambiente a direitos humanos. 3. A justiciabilidade do direito a um meio ambiente saudável. 4. O direito a um meio ambiente saudável no caso Ihaka honhat. Conclusão. Referências 


\section{INTRODUÇÃO}

Uma vez que a Convenção Americana sobre Direitos Humanos ("CADH" ou "Convenção") não prevê o direito a um meio ambiente saudável como um direito diretamente justiciável, a Corte Interamericana de Direitos Humanos ("CtIDH" ou "Corte") tem lidado apenas obliquamente com questões ambientais na sua jurisprudência. ${ }^{1}$ Os direitos econômicos, sociais, culturais e ambientais (DESCA) foram consolidados definitivamente no Sistema Interamericano através do Protocolo de São Salvador, em 1999. ${ }^{2}$

O Protocolo confere jurisdição à Corte somente em relação a direitos sindicais e ao direito à educação (artigo 19.6), excluindo, portanto, a possibilidade de uma petição individual sobre violações ao direito a um meio ambiente saudável consagrado no artigo 11 do Protocolo. ${ }^{3}$ Tradicionalmente, as questões ambientais que apareciam perante a CtIDH eram associadas ou com o direito à vida, com o direito à propriedade privada ou com o direito de acesso à informação. ${ }^{4} \mathrm{Na}$ sua Opinião

\footnotetext{
1 Sobre essa questão, veja PAVONI. R. Environmental Jurisprudence of the European and Inter-American Courts of Human Rights. In: BOER. B. (ED.), Environmental Law Dimensions of Human Rights, Oxford, 2015. Para uma perspectiva europeia, veja SCOVAZZI, T. L'interpretazione e l'applicazione "ambientalista” della Convenzione europea dei diritti umani, con particolare riguardo al caso "Urgenda". Rivista Giuridica dell'Ambiente, 2019, pp. 619-633.

2 Assinado em 1988, o Protocolo entrou em vigor apenas em 1999, quando onze Estados depositaram seus respectivos instrumentos de ratificação ou adesão, em acordo com o artigo 21 do Protocolo.

3 O artigo 19.6 do Protocolo de São Salvador diz o seguinte: "Caso os direitos estabelecidos na alínea " $a$ " do artigo $8^{\circ}$, e no artigo 13, forem violados por ação que pode ser atribuída diretamente a um Estado-Parte neste Protocolo, essa situação poderia dar origem, mediante a participação da Comissão Interamericana de Direitos Humanos e, quando for cabível, da Corte Interamericana de Direitos Humanos, à aplicação do sistema de petições individuais regulado pelos artigos 44 a 51 e 61 a 69 da Convenção Americana sobre Direitos Humanos".

4 Veja, por exemplo, CTIDH. Case of the Kaliña and Lokono Peoples v. Suriname, Merits, Reparations and Costs, Judgment of November 25, 2015. Series C No. 309; CTIDH. Case of Kichwa Indigenous People of Sarayaku v. Ecuador, Merits and Reparations, Judgment of June 27, 2012. Series C No. 245; e CTIDH. Case of Salvador Chiriboga v. Ecuador, Preliminary Objections and Merits, Judgment of May 6, 2008 Series C No. 179. Sobre essa questão, GamboA, J. G. Medio Ambiente frente a la Corte Interamericana de Derechos Humanos: una ventana de protección. In: CAnÇAdo Trindade, A. A.; BARros LEAL, C. (EDS). Derechos Humanos y Medio Ambiente. Fortaleza, 2017, pp. 103-144, e AnTKowiAK, T. A "Dignified Life" and the Resurgence of Social Rights. Journal of Human Rights, Vol. 18, 2020, pp. 1-51. A Corte Europeia de Direitos Humanos desenvolveu uma jurisprudência similar, uma vez que o direito autônomo a um meio ambiente saudável também não está presente na Convenção Europeia de Direitos Humanos. Veja, nesse sentido, PEDERSEn, O. W. The European Court of Human Rights and International Environmental Law. In: KNOX, J. H.; PEJAn, R. (eds.) The Human Right to a Healthy Environment. Cambridge, 2018, pp. 97-121. O Sistema
} 
Consultiva 23 sobre o Meio Ambiente e Direitos Humanos ("OC-23/17"), de 2017, a CtIDH introduziu peremptoriamente o tópico da proteção ambiental à sua jurisprudência através do reconhecimento do direito a um meio ambiente saudável como um direito independente e justiciável.

Originalmente solicitada pela Colômbia em relação a projetos de infraestrutura de larga escala que criavam um risco de dano ambiental significativo ao meio ambiente marinho da Região do Caribe, a opinião OC-23/17 contribuiu de diferentes maneiras para o direito da proteção ambiental dentro do Sistema Interamericano. Embora as indagações principais formuladas pela Colômbia abordassem a interpretação do termo "jurisdição" no artigo 1.1 da CADH e obrigações dos Estados relativas aos deveres de respeitar e assegurar os direitos à vida e à integridade pessoal em relação a danos ambientais, a CtIDH esclareceu várias obrigações substantivas e processuais sobre proteção ambiental decorrentes da CADH.

Ademais, a CtIDH apresentou a possibilidade de proteger direitos ambientais ao constatar que o direito a um meio ambiente saudável se enquadra no âmbito do artigo 26 da Convenção - a norma do "desenvolvimento progressivo" pela qual Estados americanos assumiram a obrigação de adotar medidas com vistas a alcançar progressivamente "a realização plena dos direitos implícitos nos padrões econômicos, sociais, educacionais, científicos e culturais". A consequência desse raciocínio é que o direito a um meio ambiente saudável agora pode ser diretamente litigado perante a CtIDH como um direito autônomo - situação que ainda não é contemplada em outros sistemas de direitos humanos. Em termos claros, através

\footnotetext{
Africano de Direitos Humanos, porém, prevê o direito a um meio ambiente saudável como um direito autônomo no artigo 24 da Carta Africana dos Direitos Humanos e dos Povos, o qual recentemente foi aplicado pela Corte Africana de Direitos Humanos e dos Povos em CADHP. African Commission on Human and People's Rights v. Republic of Kenya. No. 006/2012, Judgment, May 26, 2017. Nesse sentido, veja KotzÉ, L. J.; DU PLESSIS, A. A. The African Charter on Human and Peoples' Rights and Environmental Rights Standards. In: Turner, S. et al (eds), Environmental Rights: The Development of Standards. Cambridge, 2019, 93-115.

$5 \mathrm{CTIDH}$, The Environment and Human Rights (State obligations in relation to the environment in the context of the protection and guarantee of the rights to life and to personal integrity - interpretation and scope of Articles 4(1) and 5(1) of the American Convention on Human Rights), Opinião Consultiva OC-23/17 de 15 de novembro de 2017. Series A No. 23. (Doravante "OC-23/17”).
} 
dessa opinião, a Corte expandiu sua jurisdição para adjudicar sobre um direito que não estava originalmente previsto na $\mathrm{CADH}$.

A opinião causou repercussões entre acadêmicos $^{6}$ e desencadeou algumas consequências práticas imediatas. $\mathrm{Na}$ decisão de 6 de fevereiro do caso das Comunidades Indígenas Membros da Associação Lhaka Honhat (Nossa Terra) v. Argentina (doravante "caso Lhaka Honhaf"), o Estado réu foi responsabilizado por violar, dentre outros, o artigo 26 da Convenção ao não respeitar o direito a um meio ambiente saudável para comunidades indígenas.

O fato de que uma corte de direitos humanos se movimentou em direção à maior proteção de direitos ambientais não é surpreendente, ${ }^{7}$ mas os caminhos tomados para assegurar tal proteção parecem estar abertos à discussão. O problema de pesquisa do presente artigo foca nas técnicas empregadas pela $\mathrm{CIDH}$ a fim de ampliar sua jurisdição no que tange à proteção do direito a um meio ambiente saudável. Metodologicamente, são analisadas as decisões da Corte, tanto em sede consultiva quanto contenciosa, bem como a literatura existente sobre o tema e as principais reações sobre as decisões analisadas. Procede-se em quatro partes. Primeiramente, faz-se um breve resumo do conteúdo da Opinião Consultiva 23/17. $\mathrm{Na}$ segunda seção, é avaliado o poder da Corte de reformular a pergunta da Colômbia e expandir seu escopo. A terceira seção lida com o reconhecimento do direito a um meio ambiente saudável como um direito diretamente justiciável sob o

6 Papantoniou, A. Advisory Opinion on the Environment and Human Rights. American Journal of International Law, Vol. 112, 2018, pp. 460-466; FERIA-TINTA, M.; MILNES, S. C. International Environmental Law for the 21st Century: The Constitutionalization of the Right to a Healthy Environment in the InterAmerican Court of Human Rights Advisory Opinion 23. Anuario Colombiano de Derecho Internacional, Vol. 12, 2019, pp. 43-84; Vega-BARBosA, G.; ABOAGYE, L. A Commentary on the Advisory Opinion of the InterAmerican Court of Human Rights on the Environment and Human Rights. DPCE Online, Vol. 34 No. 1, 2018, pp. 291-297; Abello-Galvis, R.; AREVAlo-RAMIREZ, W. Inter-American Court of Human Rights Advisory Opinion OC-23/17: Jurisdictional, procedural and substantive implications of human rights duties in the context of environmental protection. Review of European, Comparative and International Environmental Law, Vol. 28, 2019, pp. 217-222; e GIANNINO, D. The Ground-Breaking Advisory Opinion OC-23/17 of the InterAmerican Court of Human Rights: Healthy Environment and Human Rights. Blog of the International Journal of Constitutional Law, 2018.

7 Veja FrAnCIONI, F. International Human Rights in an Environmental Horizon. European Journal of International Law, Vol. 21, No. 1, 2019, pp. 41-55; BoYLE, A. Human Rights and the Environment: Where Next?. In: BoER, B. (ED.), Environmental Law Dimensions of Human Rights, Oxford, 2015, pp. 201-239. Enquanto que há margem para comparação entre a Corte Europeia de Direitos Humanos e a Corte Interamericana de Direitos Humanos, o foco do presente estudo será apenas a CTIDH. 
artigo 26 da $\mathrm{CADH}$. A quarta seção analisa a aplicação do direito a um meio ambiente saudável e direitos conectados (o direito à água, por exemplo) no caso Lhaka Honhat. Conclui-se explorando as possíveis consequências dos argumentos adotados pela CIDH em relação à sua função consultiva, e as críticas à abordagem da Corte, no que diz respeito a questões ambientais, recebidas por alguns juízes.

\section{A CONTRIBUIÇÃO DA OPINIÃO CONSULTIVA № 23 SOBRE MEIO AMBIENTE E DIREITOS HUMANOS PARA O DIREITO INTERAMERICANO DE DIREITOS HUMANOS}

A crescente jurisprudência ambiental de cortes internacionais de direitos humanos atesta a tendência inevitável de conectar direitos individuais com a proteção do meio ambiente. Como foi observado com autoridade, "a relação entre direitos humanos e o meio ambiente tem evoluído rapidamente ao longo das últimas cinco décadas, e ainda mais nos últimos cinco anos. A ecologização de direitos humanos bem estabelecidos (...) tem contribuído para melhorias na saúde e no bem-estar de pessoas ao redor do mundo". ${ }^{8}$ O mesmo é particularmente verdadeiro para 0 continente americano, onde problemas ambientais graves ocupam parte importante da preocupação pública. Consequentemente, o Sistema Interamericano de Direitos Humanos tem aumentado gradualmente seu alcance sobre questões ambientais. ${ }^{9}$

\footnotetext{
8 Do original: "the relationship between human rights and the environment has evolved rapidly over the past five decades, and even more so over the past five years. The greening of well-established human rights, (...) has contributed to improvements in the health and well-being of people across the world". (CONSELHO DE DIREITOS HUMANOS. Report of the Special Rapporteur on the issue of human rights obligations relating to the enjoyment of a safe, clean, healthy and sustainable environment, John H. Knox, 19 de julho de 2018, UN Doc A/73/188, para. 53, p. 15). Veja também CONSELHO DE DIREITOS HUMANOS. Mapping report of the Independent Expert on the issue of human rights obligations relating to the enjoyment of a safe, clean, healthy and sustainable environment, John H. Knox, 30 de dezembro de 2013, UN Doc. A/HRC/25/53.

9 Nesse sentido, veja SHELTON, D. Derechos ambientales y obligaciones en el sistema interamericano de derechos humanos. Anuario de Derechos Humanos, $\mathrm{N}^{\circ}$. 6, 2010, pp. 111-127; LÓPEZ ZAMORA, L. A. El enfoque extractivo del derecho ambiental y los desafios del concepto de "pueblos indígenas". Anuario Mexicano de Derecho Internacional, Vol. XIX, 2014, pp. 301-345; CAMPILLAY, E. A. G. Derecho a vivir en un medio libre de contaminación o medio ambiente sano como Derecho Humano ante la jurisprudencia y Comisión de la Corte Interaméricana de Derechos Humanos. Cuadernos de Extensión Jurídica, Vol. 28, 2016, pp. 99-119.
} 
A Opinião Consultiva OC-23/17, emitida pela CIDH em 15 de novembro de 2017, galvanizou grande parte desse debate através do pronunciamento oficial da Corte.

Em resumo, a Opinião lidou principalmente com dois tópicos. Em primeiro lugar, havia a questão de se o termo "jurisdição" no artigo $1.1^{10}$ da CADH também compreendia jurisdição extraterritorial para fins de responsabilidade dos Estados. A pergunta levantada pela Colômbia nesse sentido se relacionava particularmente aos possíveis efeitos sobre os direitos humanos que projetos de infraestrutura em larga escala na área do Caribe poderiam gerar fora do território nacional de um Estado, ou o potencial efeito além do território de um Estado. A preocupação da Colômbia era que, devido às suas dimensões e permanência, tais projetos poderiam causar danos transfronteiriços significativos, afetando pessoas em toda a região e seu gozo dos direitos consagrados na Convenção.

Aplicando os artigos 31 e 32 da Convenção de Viena sobre o Direito dos Tratados para interpretar a palavra "jurisdição", a Corte chegou à conclusão de que o termo não se limita à jurisdição territorial. Abrange também "um conceito mais amplo que inclui certas maneiras de exercitar a jurisdição além do território do Estado em questão". ${ }^{11}$ Apoiando-se na jurisprudência da Corte Europeia de Direitos Humanos (CEDH), ${ }^{12}$ a Corte Interamericana concluiu que o termo jurisdição "abrange qualquer situação na qual um Estado exerce controle ou autoridade efetiva sobre uma pessoa ou pessoas, tanto dentro quanto fora de seu território". ${ }^{13}$ Consequentemente, "indivíduos cujos direitos consagrados pela Convenção foram violados devido a dano transfronteiriço estão sujeitos à jurisdição do Estado de

$10 \mathrm{O}$ artigo 1.1 da CADH diz o seguinte: “Os Estados Partes nesta Convenção comprometem-se a respeitar os direitos e liberdades nela reconhecidos e a garantir seu livre e pleno exercício a toda pessoa que esteja sujeita à sua jurisdição, sem discriminação alguma por motivo de raça, cor, sexo, idioma, religião, opiniões políticas ou de qualquer outra natureza, origem nacional ou social, posição econômica, nascimento ou qualquer outra condição social".

$11 \mathrm{CTIDH}, O C-27 / 17$, para. 74.

12 CTIDH, OC-27/17, para. 79. A CTIDH baseou seus argumentos majoritariamente em CEDH. Loizidou v. Turkey (Preliminary objections), Al-Skeini and Others v. The United Kingdom, Catan and Others v. Moldova and Russia; Chiragov and Others v. Armenia. Sobre essa questão, veja MILANOVIC, M. Extraterritorial Application of Human Rights Treaties: Law, Principles and Policy, Oxford, 2011; BESSON, S. The Extraterritoriality of the European Convention on Human Rights: Why Human Rights Depend on Jurisdiction and What Jurisdiction Amounts to. Leiden Journal of International Law, Vol. 25, 2012, pp. 857-884.

$13 \mathrm{CTIDH}, O C-23 / 17$, para. 104, a. 
origem do dano, porque este Estado exerce controle efetivo sobre as atividades realizadas em seu território ou sob sua jurisdição". ${ }^{14}$

É o primeiro caso no qual a CtIDH reconheceu a possibilidade da aplicação extraterritorial da $\mathrm{CADH} .{ }^{15}$ Notadamente, parece ter sido inspirada pela sua contraparte europeia. Em consonância com a jurisprudência da CEDH, a CtIDH ressaltou o caráter excepcional da jurisdição extraterritorial, a qual requer uma "interpretação restritiva" sob a luz das "circunstâncias particulares do caso em específico". ${ }^{16}$

A segunda questão principal abordada pela OC-23/17 foi o esclarecimento de quais obrigações ambientais estavam conectadas à proteção dos direitos à vida (artigo 4) e à integridade pessoal (artigo 5) sob a CADH. A partir de uma interpretação teleológica da pergunta feita pela Colômbia, a Corte aproveitou a oportunidade para esclarecer uma série de questões relativas às obrigações ambientais em matéria de direitos humanos no continente americano.

Após reafirmar a conexão entre direitos humanos e proteção ambiental, a Corte invocou seus pronunciamentos anteriores que reconhecem que a proteção ambiental é uma condição para uma vida digna. ${ }^{17}$ No entanto, a Corte foi além e reconheceu um conjunto de obrigações adicionais relativas aos artigos 4 e 5 da CADH. Baseando-se fortemente nas Declarações de Estocolmo e do Rio, ela identificou diversas obrigações de devida diligência (due diligence) decorrentes da Convenção. ${ }^{18}$

Além de reconhecer o direito autônomo a um meio ambiente saudável estabelecido na Convenção, a Corte delimitou mais obrigações, especificando seu conteúdo,

14 CTIDH, OC-23/17, para. 104, d.

15 A Comissão Interamericana de Direitos Humanas já aplicou previamente esta interpretação em: CTIDH. Franklin Guillermo Aisalla Molina (Ecuador v. Colombia). Admissibility Report No. 112/10 of October 21, 2011, para. 91; e CTIDH, Case of Coard et al. v. United States. Merits Report No. 109/99 of September 29, 1999, para. 37.

16 CTIDH, $O C-23 / 17$, para. 81.

17 A Corte citou os seguintes casos: Caso da Comunidade Indígena Yakye Axa v. Paraguai, Caso da Comunidade Indígena Xákmok Kásek v. Paraguai e Caso dos Povos Kalinã e Lokono v. Suriname.

18 CTIDH. OC-23/17, paras. 123 e 124. 
alcance e aplicação sob o Sistema Interamericano. ${ }^{19}$ Por exemplo, para proteger o direito humano à vida e à integridade pessoal, Estados precisam conduzir avaliações sobre impactos ambientais quando confrontados com riscos ao meio ambiente e estão sob o dever de preparar um plano de contingência em relação a possíveis desastres ambientais. Eles também têm o dever de mitigar qualquer dano ambiental significativo que ocorra dentro de seu território. Ademais, especificamente em relação à proteção dos direitos à vida e à integridade pessoal, a Corte enfatizou a obrigação dos Estados de cooperar para assegurar a proteção contra dano transfronteiriço significativo, bem como dos direitos individuais de acesso à informação e à participação pública. ${ }^{20}$

De maneira bastante inovadora, a CIDH também estabeleceu que Estados americanos "devem agir de acordo com o princípio da precaução para proteger os direitos à vida e à integridade pessoal", ${ }^{21}$ o que caracteriza um passo à frente no longo debate sobre esse princípio no direito internacional. ${ }^{22} \mathrm{O}$ raciocínio se baseou no fato de que, ao interpretar a Convenção, a Corte deve buscar a "melhor perspectiva para a proteção do indivíduo", o que significa que "os Estados devem atuar conforme ao princípio de precaução, a efeitos da proteção do direito à vida $\mathrm{e}$ à integridade pessoal, em casos onde tenha indicadores admissíveis que uma atividade poderia acarretar danos graves e irreversíveis ao meio ambiente, ainda em ausência de certeza científica". ${ }^{23}$

É difícil evitar a impressão de que a Corte desempenhou uma função quase legislativa ao identificar essa "lista de obrigações" decorrentes do direito ambiental internacional e ao conectá-las aos artigos 4 e 5 da CADH. Cada uma das obrigações

19 Para uma análise detalhada, veja FERIA-TINTA, M.; MILNES, C., supra, p. 55 ss.

20 A "lista completa" de obrigações foi resumida pela Corte em: CTIDH. OC-23/17, para. 242.

21 CTIDH, OC-23/17, dispositif, para. 6.

22 TReves, T.Environmental Impact Assessment and the Precautionary Approach: Why Are International Courts and Tribunals Reluctant to Consider Them as General Principles of Law?. In: ANDENAS, M.; FITZMAURice, M.; TANZI, A.; Wouters, J. (eds.). General Principles and the Coherence of International Law, Leiden, 2019, pp. 379-388. Veja também CANÇADO Trindade, A. A. Principle 15: Precaution. In: VIÑUALES, J. (Ed.) Rio declaration on environment and development: a commentary, 2015, pp. 403-428; Foster, C. E. Science and the Precautionary Principle in International Courts and Tribunals. Cambridge, 2011, p. 18.

23 CTIDH, $O C-23 / 17$, para. 180. 
supracitadas foi delineada detalhadamente na Opinião. A Corte se baseou em fontes diferentes para detalhar o conteúdo específico de cada obrigação, realizando pouca ou nenhuma distinção entre tratados, decisões judiciais ou soft law, apesar de suas observações de que instrumentos de soft law "fornecem orientação sobre a interpretação dos primeiros, porque eles dão maior precisão ao conteúdo básico estabelecido nos tratados". ${ }^{24}$

Estabelecido o conteúdo da Opinião, passa-se à análise de duas técnicas empregadas pela Corte para expandir seu alcance sobre obrigações e direitos ambientais: a expansão do escopo da questão levantada pela Colômbia e a introdução do direito autônomo a um meio ambiente saudável, de acordo com o artigo 26 da Convenção.

\section{EXPANDINDO O ESCOPO DA QUESTÃO: CONECTANDO O MEIO AMBIENTE A DIREITOS HUMANOS}

Uma das características distintivas da função consultiva da CIDH é permitir aos Estados (dentre outros sujeitos) solicitem opiniões consultivas diretamente. $O$ artigo 64 da CADH estabelece que "os Estados-Membros da Organização podem consultar a Corte sobre a interpretação desta Convenção ou outros tratados relativos à proteção de direitos humanos nos Estados americanos". Essa possibilidade tem sido amplamente explorada pelos Estados no continente americano. Apenas em raras ocasiões a Corte se recusou a emitir uma opinião consultiva. Não por acaso comentaristas têm apontado uma tendência expansiva na jurisdição consultiva da Corte, a qual também tocou em assuntos delicados na agenda doméstica dos Estados americanos. ${ }^{25}$

24 CTIDH, $O C-23 / 17$, para. 45.

25 Veja, por exemplo, Schmid, J. C. Advisory Opinions on Human Rights: Moving Beyond a Pyrrhic Victory, Duke Journal of Comparative \& International Law. Vol. 16, 2006, pp. 415-456; RoA, J. E. La función consultiva de la Corte Interamericana de Derechos Humanos. Bogotá, 2015; e AstA, G. La funzione consultiva delle corti regionali dei diritti umani. Napoli, 2019. Veja também BUERGENTHAL, T. The Advisory Practice of the Inter-American Human Rights Court, American Journal of International Law. Vol. 79, 1985, pp. 1-27; e BAILLIET, C. The strategic prudence of The Inter-American Court of Human Rights: rejection of requests for an advisory opinion. Revista de Direito Internacional, Vol. 15, 2018, p. 254. 
Diante de um pedido de opinião, a Corte geralmente se inclina a fazer pronunciamentos um pouco além do escopo da questão formulada originalmente. Este também parece ser o caso na Opinião Consultiva 23. Para poder se pronunciar sobre as obrigações ambientais que vinculam as partes à Convenção Americana, a Corte adotou três passos: (a) reformulou e ampliou a questão perguntada pela Colômbia; (b) adotou uma abordagem funcional ao definir o propósito de sua jurisdição consultiva; e (c) conectou direitos humanos à proteção do meio ambiente.

a) A Corte invocou seu poder estabelecido de reformular as questões colocadas a ela ${ }^{26}$ a fim de ampliar o escopo da opinião. Embora as três perguntas da Colômbia fossem diretamente relacionadas à Convenção de Cartagena ${ }^{27}$ e a proteção do meio ambiente marinho, a CtIDH primeiro reformulou, ampliou e fundiu as questões da Colômbia ${ }^{28}$ e, então, ao invés de fazer uma declaração precisa em relação a áreas protegidas sobre direitos aplicáveis de direito ambiental internacional, passou a "identificar, de maneira clara e sistemática, as obrigações dos Estados em relação à proteção do meio ambiente dentro do âmbito da sua obrigação de respeitar e assegurar os direitos humanos de todas as pessoas sujeitas à sua jurisdição". ${ }^{29}$ Apesar de esse poder de reformular frequentemente tem sido utilizado por cortes internacionais, a maneira pela qual a Corte procedeu parece ser questionável por dois motivos.

Primeiramente, ao ampliar as questões formuladas, a Corte se pronunciou sobre assuntos delicados sem ter dado aos Estados e outros sujeitos do Sistema

26 A Corte citou sua jurisprudência anterior ao observar que "a maneira pela qual um pedido é redigido pode exigir que a Corte, ao exercer suas funções sob o artigo 64 da Convenção, defina ou esclareça e, em certos casps, reformule as questões submetidas a ela a fim de verificar o que, precisamente, está sendo perguntado". Em CTIDH. Enforceability of the Right of Reply or Rectification (Arts. 14.1, 1.1 and 2 American Convention on Human Rights), Opinião Consultiva OC-07/86 de 29 de agosto de 1986. Series A No. 7, para. 12; e CTIDH. The Right to Information on Consular Assistance in the Framework of the Guarantees of the due Process of Law, Opinião Consultiva OC-16/99 de 01 de outubro de 1999. Series A No. 16, para. 1999.

27 A Convenção para a Proteção e Desenvolvimento do Meio Ambiente Marinho na Região do Caribe, ou Convenção de Cartagena, é um tratado regional para a proteção do Mar do Caribe. Foi adotada em Cartagena, na Colômbia, em 24 de março de 1983 e entrou em vigor em 11 de outubro de 1986 e foi ratificada por 26 Estados-Membros na Região do Caribe. Além de determinações gerais que visam garantir uma "boa gestão ambiental", abrange vários tópicos como a poluição causada por navios, despejos e fontes terrestres, e estabelece outras obrigações relativas ao direito ambiental internacional.

28 CTIDH, $O C-23 / 17$, paras. 32 a 38.

29 CTIDH, $O C-23 / 17$, para. 23. 
Interamericano uma possibilidade real de oferecer contribuições em relação à questão específica do conteúdo dos direitos e obrigações ambientais advindas da CADH. É contundente a crítica do juiz Sierra Porto, expressa no seu voto concorrente (concurring opinion), de que "a maioria excede o propósito da Opinião Consultiva, sem garantir àqueles que intervêm no processamento da Opinião Consultiva qualquer oportunidade de apresentar argumentos contra ou a favor desta posição" ${ }^{30}$ De fato, apenas quatro Estados do Sistema Interamericano apresentaram observações - todas em relação ao meio ambiente marinho e a Convenção de Cartagena e os artigos 4 e 5 da CADH. Isto não é surpreendente, dado ao interesse limitado vinculado ao pedido muito específico proposto pela Colômbia. Deve-se conceder que a CtIDH recebeu uma variedade de submissões de diferentes atores: dois órgãos da Organização dos Estados Americanos, a Organização Marítima Internacional, Organizações Não-Governamentais (ONGs) e Organizações de Sociedade Civil (OSCs), bem como de acadêmicos e clínicas jurídicas. Essa é discutivelmente uma participação muito ampla que revela sério interesse no assunto. Contudo, ao fim do dia, o número de Estados participantes nos procedimentos foi muito restringido. No fim das contas, eles serão os que resistirão aos eventuais julgamentos na Corte no futuro. Pode-se pelo menos argumentar que se eles soubessem que a Corte delimitaria obrigações ambientais gerais ao invés de responder os pedidos da Colômbia relativos ao meio ambiente marinho, poder-se-ia esperar um nível diferente de participação. A abordagem da Corte revela a necessidade de incentivar mais participação pública quando uma corte internacional muda significativamente a pergunta colocada a ela sem conscientizar os membros do sistema sobre as consequências em jogo.

O segundo problema diz respeito aos limites entre a jurisdição consultiva da Corte e disputas em curso perante outras cortes internacionais, algo que tem sido um problema recorrente na jurisprudência da CtIDH desde suas primeiras opiniões consultivas. É difícil evitar a impressão de que a pergunta da Colômbia poderia ter tido um impacto nas controvérsias entre esta e a Nicarágua sobre a construção de

30 CTIDH, OC-23/17, Concurring Opinion of Judge Sierra Porto, para. 7. 
megaprojetos e o caso pendente perante a $\mathrm{ClJ} .{ }^{31} \mathrm{~A}$ Corte foi informada desse fato por intervenção da Guatemala, a qual alegou ser necessário "considerar, dentro desse pedido, a possível implicação do Estado da Nicarágua, ainda que isso não esteja expressamente indicado em qualquer parte do documento" 32 , e também que "a interpretação fornecida em resposta ao pedido deve estar de acordo com o que tem sido indicado no decorrer desses procedimentos entre Colômbia e Nicarágua; sempre respeitando os direitos humanos e a soberania dos Estados que possam estar envolvidos". ${ }^{33}$ A Corte abordou este ponto simplesmente ao recordar que, de acordo com sua jurisprudência, o exercício de sua função consultiva "não pode ser restringido por casos contenciosos instituídos perante a Corte Internacional de Justiça". ${ }^{34} \mathrm{O}$ desejo de evitar pronunciamentos sobre tópicos relativos a uma controvérsia pendente pode explicar por que a Corte preferiu ampliar a questão perguntada. Porém, o resultado ainda pode ter um impacto sobre a controvérsia pendente - pelo menos no que tange a obrigações ambientais.

(b) O segundo argumento colocado pela Corte para justificar sua decisão de fazer um pronunciamento sobre as obrigações ambientais decorrentes da CADH é fundamentado em uma abordagem funcional. Visto que uma das funções da Corte é "ajudar os Estados-Membros e órgãos da OEA a cumprir plena e efetivamente com suas obrigações internacionais relevantes, e definir e implementar políticas públicas para proteger direitos humanos", a declaração final da Corte "ajudaria a fortalecer o sistema para a proteção de direitos humanos". ${ }^{35}$ No entanto, esse argumento é um tanto quanto frágil: fortalecer o sistema para a proteção de direitos humanos não implica automaticamente a competência para interpretar instrumentos relacionados ao direito ambiental internacional. De acordo com a Convenção, a

31 CORTE INTERNACIONAL DE JUSTIÇA, Alleged Violations of Sovereign Rights and Maritime Spaces in the Caribbean Sea (Nicaragua v. Colombia).

32 CTIDH, $O C-23 / 17$, para. 25.

33 CTIDH, $O C-23 / 17$, para. 25.

34 CTIDH, OC-23/17, para. 26. No mesmo sentido, Opinião Consultiva OC-16/99, para. 61.

35 CTIDH, OC-23/17, para. 24. 
jurisdição consultiva da Corte é limitada à CADH e "outros tratados concernentes à proteção dos direitos humanos nos Estados americanos". ${ }^{36}$

(c) Para superar essa dificuldade, a Corte se esforçou para esclarecer a conexão entre direitos humanos e o meio ambiente em uma parte longa da opinião. $O$ argumento da Corte começou com uma referência a diversos documentos internacionais de diferentes fontes e órgãos interligando direitos humanos com a proteção do meio ambiente. ${ }^{37} \mathrm{~A} \mathrm{CtIDH}$ concluiu que ela "se pronunciará sobre as obrigações dos Estados relativas ao meio ambiente que são mais relacionadas à proteção de direitos humanos, o que é a função principal desta Corte. Consequentemente, ela se referirá às obrigações ambientais decorrentes das obrigações de respeitar e assegurar os direitos humanos". ${ }^{38}$ Porém, da mesma forma, a CtIDH observou que, para identificar as obrigações dos Estados, uma "consequência da interdependência e indivisibilidade dos direitos humanos e a proteção ambiental é que (...) a Corte pode se valer dos princípios, direitos e obrigações do direito ambiental internacional". ${ }^{39}$

A referência a fontes externas não é uma técnica rara empregada pela $\mathrm{CtIDH}$. A título de exemplo, em várias ocasiões a Corte se referiu às Quatro Convenções de Genebra de 1949, as quais "poderiam ser levadas em consideração como elementos de interpretação da Convenção Americana". 40 Seja como for, ao caracterizar o direito ambiental internacional como "parte do copus iuris internacional" e identificar o conteúdo e escopo das obrigações nele contidas, é difícil traçar uma linha onde a Corte considera regras externas (i.e., regras não

$36 \mathrm{CADH}$, artigo 64.

37 CTIDH, OC-23/17, para. 52. Uma abordagem normalmente empregada na jurispruência da Corte mas também no campo do direito ambiental internacional. Nesse sentido, veja também BRUNEÉ, J. The Sources of International Environmental Law: Interactional Law. In: BESSON, S; D'ASPREMONT, J. (eds.). The Oxford Handbook on Sources of International Law. Oxford, 2017, pp. 960-983.

$38 \mathrm{CTIDH}, O C-23 / 17$, para. 35.

39 CTIDH, $O C-23 / 17$, para. 55 .

40 CTIDH. Case of the Santo Domingo Massacre v. Colombia. Preliminary Objections, Merits and Reparations, Judgment of November 30, 2012. Series No. 259, para. 23. Nesse mesmo sentido, veja CTIDH. Case of the Massacres of El Mozote and surrounding areas v. El Salvador. Merits, Reparations and Costs, Judgment of October 25, 2012. Series C No. 252, para. 141. 
colocadas diretamente pela Convenção) "como elementos de interpretação" ou seu próprio direito aplicável. ${ }^{41}$

As implicações da abordagem expansiva da Corte e seu uso dos três argumentos supracitados parecem ser pelo menos duplas. Primeiro, ao redefinir a questão, alinhando-a com os debates ocorrendo em nível universal (especialmente com as recomendações do Conselho de Direitos Humanos das Nações Unidas), ${ }^{42}$ a Corte se empoderou com a capacidade de interpretar um novo ramo do direito internacional: o direito ambiental internacional. $O$ fato de que algumas das obrigações identificadas pela Corte se apoiam em fontes diferentes parece confirmar esta conclusão. A título de ilustração, a Corte elaborou extensivamente sobre os requerimentos para a condução de avaliações sobre impactos ambientais, estabelecendo padrões citados ou na jurisprudência recente da CIJ ou na legislação nacional de Estados americanos e do Programa das Nações Unidas para o Meio Ambiente. ${ }^{43}$ Ademais, a Corte não fez distinção entre a autoridade de obiter dicta e a parte dispositiva das suas opiniões consultivas. ${ }^{44}$ Assim, a segunda conclusão é que os pronunciamentos importantes sobre obrigações ambientais internacionais podem ser bem utilizados pela CtIDH nos casos individuais futuros como jurisprudência autoritativa.

\section{A JUSTICIABILIDADE DO DIREITO A UM MEIO AMBIENTE SAUDÁVEL}

\footnotetext{
41 Sobre essa questão, veja LIXINSKI, L. Treaty Interpretation by the Inter-American Court of Human Rights: Expansionism at the Service of the Unity of International Law. European Journal of International Law, Vol. 21, 2010, p. 604, para o qual "The use of foreign instruments is more often than not a search for external validation rather than an actual excursion into waters not charted by the American Convention. New dimensions are added to pre-existing rights, but rarely does the Court actually engage in creating new rights. The Court seems very aware of the need to place itself in a larger normative universe and use that to advance its mandate of human rights protection, but it is very cautious not to strain it". Veja também BURGORGUE-LARSEN, L. "Decompartmentalization": The key technique for interpreting regional human rights treaties. International Journal of Constitutional Law, Vol. 16, 2018, p. 187-213.

42 Veja supra, nota 8.

43 CTIDH, OC-23/17, paras. 156-179.

44 Há certo criticismo sobre essa questão. Veja, por exemplo, EstuPIÑan SILVA, R. Primera opinión interamericana sobre medio ambiente: ¿derecho exigible o decisión ultra vires?. Criterio Jurídico Garantista, Vol. 11, pp. 61-80.
} 
A CtIDH e a Comissão Interamericana têm suas competências definidas para conhecer reivindicações individuais advindas de violações à CADH. O artigo 44 da $\mathrm{CADH}$ estabelece que os indivíduos e outras entidades podem "apresentar à Comissão petições que contenham denúncias ou queixas de violação desta Convenção por um Estado Parte". ${ }^{45}$ Correspondentemente, o artigo 62 da Convenção determina que "a Corte tem competência para conhecer de qualquer caso relativo à interpretação e aplicação das disposições desta Convenção". ${ }^{46}$ Porém, na OC-23/17, a CtIDH reconheceu que o direito a um meio ambiente saudável é um direito autônomo justiciável abrangido pelo artigo 26 da Convenção. ${ }^{47} \mathrm{Em}$ outras palavras, a Corte reconheceu que indivíduos e outras entidades podem discutir violações ao direito a um meio ambiente saudável diretamente usando o artigo 26. Essa disposição prescreve o seguinte:

Os Estados Partes comprometem-se a adotar providências, tanto no âmbito interno como mediante cooperação internacional, especialmente econômica e técnica, a fim de conseguir progressivamente a plena efetividade dos direitos que decorrem das normas econômicas, sociais e sobre educação, ciência e cultura, constantes da Carta da Organização dos Estados Americanos, reformada pelo Protocolo de Buenos Aires, na medida dos recursos disponíveis, por via legislativa ou por outros meios apropriados.

Comentaristas enfatizaram o caráter programático do artigo 26 e a pouca atenção que ele recebeu no passado devido ao seu conteúdo vago e aplicação rara. ${ }^{48}$ Contudo, na sua jurisprudência recente, a Corte recorreu ao artigo 26 a fim de reconhecer outros direitos não previstos explicitamente na Convenção, especialmente direitos econômicos, sociais, culturais e ambientais (DESCA). Por

45 Artigo 44, CADH, ênfase adicionada.

46 Artigo 62, CTIDH, ênfase adicionada.

47 No contexto da Corte Europeia de Direitos Humanos, não foi seguida qualquer abordagem similar.

48 COURTIS, C. Artículo 26 - Desarrollo Progresivo. In: STEINER, C.; URIBE, P. (eds.). Convención Americana sobre Derechos Humanos Comentada,.Mexico, 2014, p. 654; CANÇADO TRINDADE, A. A. A justiciabilidade dos direitos económicos, sociais e culturais no plano internacional. In: Presente y futuro de los Derechos Humanos. Ensayos en honor a Fernando Volio Jiménez, Instituto Interamericano de Derechos Humanos, San José, 1998; BURGORGUE-LARSEN, L. Economic and social rights. In: BURGORGUELARSEN, L; ÚBEDA DE TORRES, A. The Inter-American Court of Human Rights: Case Law and Commentary. Oxford, 2011, pp. 613-641. 
exemplo, a jurisprudência recente da CtIDH lidou com o direito à saúde ${ }^{49}$ e direitos trabalhistas como direitos independentes. ${ }^{50}$ Este exercício de ler nessa disposição direitos não expressamente previstos na Convenção gerou controvérsia sobre a jurisdição da CtIDH em relação aos DESCA. ${ }^{51}$

Embora o artigo 26 não mencione o direito a um meio ambiente saudável ou mesmo a palavra "ambiental" no texto, o artigo 11 do Protocolo de São Salvador (PSS) de 1988 claramente o reconhece. De acordo com este, "toda pessoa tem direito a viver em meio ambiente sadio e a dispor dos serviços públicos básicos" e "os EstadosPartes [do Protocolo] promoverão a proteção, preservação e melhoramento do meio ambiente". O problema é que a CtIDH não tem jurisdição sobre os direitos previstos no PSS de acordo com o artigo 62 da Convenção. Seja como for, a CtIDH, na OC23/17, aproveitou a oportunidade para declarar que o artigo 26 da CADH também abrange o direito a um meio ambiente saudável protegido pelo artigo 11 do Protocolo de São Salvador. ${ }^{52}$ Por consequência, o direito a um meio ambiente saudável agora é um direito justiciável perante a CtIDH.

A Corte empregou dois argumentos para incluir o artigo 11 do PSS no artigo 26. Primeiramente, a Corte raciocinou sistemicamente que o artigo 11:

"também deve ser considerado incluído entre os direitos econômicos, sociais e culturais protegidos pelo artigo 26 da Convenção Americana, como sob tal norma se encontram protegidos aqueles direitos que se derivam das normas econômicas, sociais e sobre educação, ciência e cultura contidas na Carta da OEA, na Declaração Americana sobre Direitos e Deveres do Homem (na medida em que esta última" contém e define aqueles direitos humanos essenciais aos que a Carta se refere") e

49 CTIDH. Caso Poblete Vilches y otros v. Chile. Merits, Reparations and Costs, Judgment of 8 March 2018, Series C No. 349, para. 110; CTIDH, Case of Cuscul Pivaral et al. v. Guatemala, Preliminary Objection, Merits, Reparations and Costs, Judgment of August 23, 2018. Series C No. 359.

50 CTIDH. Case Lagos del Campo v. Peru, Preliminary Objections, Merits, Reparations and Costs, Judgment of August 31, 2017. Series C No. 340; CTIDH. Case of Muelle Flores v. Peru, Preliminary Objections, Merits, Reparations and Costs, Judgment of March 6, 2019. Series C No. 375.

51 DE PAZ GonZÁlez, I. The Social Rights Jurisprudence in the Inter-American Court of Human Rights: Shadow and Light in International Human Rights. Cheltenhan, 2018; RUIZ-CHIRIBOGA, O. R. The American Convention and the Protocol of San Salvador: Two Intertwined Treaties: Non-Enforceability of Economic, Social and Cultural Rights in the Inter-American System. Netherlands Quarterly of Human Rights, Vol. 31, 2, 2017, pp. 159-186.

52 CTIDH, $O C$-23/17, paras. 56 e 57. Nas palavras da Corte: "este direito [a um meio ambiente saudável] também deve ser considerado incluído entre os direitos econômicos, sociais e culturais protegidos pelo artigo 2683 da Convenção Americana (...)". 
os que se derivem de uma interpretação da Convenção conforme com os critérios estabelecidos no artigo 29 da mesma." 53

A referência ao artigo 29 da CADH é reveladora. Este estabelece que "nenhuma disposição desta Convenção pode ser interpretada no sentido de: (...) (d) excluir ou limitar o efeito que possam produzir a Declaração Americana dos Direitos e Deveres do Homem e outros atos internacionais da mesma natureza". Em uma nota de rodapé, a CtIDH cita o caso Lagos del Campo no qual, pela primeira vez, incluiu-se o direito ao trabalho no artigo 26 da Convenção, utilizando a interpretação do artigo 29. A mesma nota de rodapé indicou que o artigo 26 "protege os direitos que se derivam da Carta da OEA, a Declaração Americana sobre Direitos e Deveres do Homem e os que se derivem de 'outros atos internacionais da mesma natureza'" ${ }^{54}$ A lógica da Corte parece ser a de que o artigo 29 (d) da Convenção, lido em conjunto com o artigo 26, confere à Corte jurisdição para adjudicar sobre outros tratados que não a Convenção.

Para reforçar seu raciocínio, a CtIDH destacou a "interdependência e indivisibilidade existente entre os direitos civis e políticos, e os econômicos, sociais e culturais, já que devem ser entendidos integralmente e de forma conglobada como direitos humanos, sem hierarquia entre si e exigíveis em todos os casos ante aquelas autoridades que resultem competentes para isso". 55 Porém, embora a indivisibilidade destes direitos seja bem reconhecida no direito internacional, menos claro é o fato de que sua justiciabilidade também está interligada - uma possível consequência da abordagem da Corte.

A abordagem da Corte levanta dois problemas: um sobre interpretação, outro sobre consentimento dos Estados.

A Corte usa as regras de interpretação da Convenção (artigo 29) em conjunto com uma leitura teleológica do artigo 26 a fim de identificar um direito não previsto expressamente na Convenção. Comentadores observaram que a CtIDH

53 CTIDH, OC-23/17, para. 57.

54 CTIDH, $O C-23 / 17$, para. 57, nota de rodapé 86.

55 CTIDH, OC-23/17, para. 57. 
desenvolveu critérios de interpretação importantes e diferentes para garantir sua função de proteger os direitos humanos no continente..$^{56} \mathrm{O}$ uso por parte da Corte de sua própria jurisprudência tem um papel importante para reforçar essas conclusões prévias. No entanto, o raciocínio da Corte parece não possuir limite claro. Embora o uso de "outros atos internacionais da mesma natureza" aparenta ser uma ferramenta importante para incorporar novos elementos de interpretação ao argumento da Corte, é difícil apoiar o raciocínio da Corte de que essa disposição permite a incorporação independente de direitos não previstos originalmente na Convenção. Da mesma forma, o juiz Sierra Porto criticou a posição da Corte ao constatar que "a amplíssima abertura que se deu ao artigo 26 da Convenção Americana excede 0 alcance do próprio artigo". ${ }^{57}$ Estados já reagiram à interpretação ampla da Corte no passado, ${ }^{58}$ embora até agora nenhuma crítica tenha aparecido especificamente em relação à opinião consultiva.

A interpretação da Corte também tem consequências relativas à questão do consentimento dos Estados à jurisdição da Corte. Uma interpretação menos expansiva sugere que os Estados não quiseram incluir a justiciabilidade dos DESCA na jurisdição da CIDH. A inclusão por parte da Corte de direitos ambientais no artigo 26 não aconteceu de maneira fácil. Ambos os juízes Vio Grossi e Sierra Porto, em seus votos dissidentes, criticaram fortemente o reconhecimento da Corte da justiciabilidade do direito a um meio ambiente saudável sob o artigo 26 da CADH. De acordo com o juiz Vio Grossi, "os direitos em comento não se encontram compreendidos ou contidos na Convenção e, portanto, não podem ser objeto do sistema de proteção que ela contempla". 59

Outro problema decorre da introdução pela Corte da justiciabilidade direta do artigo 11 do PSS no artigo 26 da CADH, no que diz respeito ao conteúdo específico do

\footnotetext{
56 Veja BURGORGUE-LARSEN e LIXINSKI, supra. Veja também RODRIGUEZ, G. Articulo 29 - Normas de Interpretación. In: STEINER, C.; URIBE, P. (eds). Convención Americana sobre Derechos Humanos Comentada. Mexico, 2014, pp.706-714.

57 CTIDH, OC-23/17, Voto Concorrente do Juiz Sierra Porto, para. 11.

58 Veja, nesse sentido, VON BOGDANDY, A.; URUEÑA, R. International Transformative Constitutionalism in Latin America. American Journal of International Law, Vol. 114, 2020, pp. 403-442; CONTESSE, J. Resisting the Inter-American Human Rights System. Yale Journal of International Law, Vol. 44, 2019 , p. 179. 59 CTIDH, OC-23/17, Voto Concorrente do Juiz Vio Grossi, para. 5.
} 
direito a um meio ambiente saudável. Conforme foi observado previamente, a Corte estabeleceu um conjunto específico de padrões para cumprir com o direito a um meio ambiente saudável na Opinião Consultiva, embaçando as linhas entre uma função judicial e uma função quase legislativa. Por exemplo, a Corte especificou que o direito a um meio ambiente saudável possui uma dimensão coletiva e uma individual. A violação à dimensão individual "pode ter repercussões diretas ou indiretas sobre as pessoas devido à sua conexão com outros direitos, tais como o direito à saúde, a integridade pessoal ou a vida". ${ }^{60}$ Adicionalmente, a Corte se apoiou no Grupo de Trabalho sobre o Protocolo de São Salvador, o órgão de monitoramento do protocolo, ${ }^{61}$ para definir com precisão o conteúdo exato do direito advindo de suas cinco obrigações:

“a) garantir a toda a pessoa, sem discriminação alguma, um meio ambiente saudável para viver; b) garantir a toda pessoa, sem discriminação alguma, serviços públicos básicos; c) promover a proteção do meio ambiente; d) promover a preservação do meio ambiente, e e) promover o melhoramento do meio ambiente. Assim mesmo, estabeleceu que o exercício do direito ao meio ambiente saudável deve ser guiado pelos critérios de disponibilidade, acessibilidade, sustentabilidade, aceitabilidade e adaptabilidade". ${ }^{6}$

Essencialmente, a Corte listou todas as obrigações e padrões internacionais que os Estados supostamente devem observar a fim de respeitar o direito a um meio ambiente saudável, de acordo com o artigo 26 da Convenção Americana.

Uma consequência problemática dessa abordagem se encontra no risco de um embate entre a CtIDH e juízes nacionais em casos futuros de direito ambiental. A título de comparação, pode-se notar que a abordagem da CEDH sobre assuntos ambientais é um tanto quanto deferente para com os Estados Partes. Reconheceuse que, no contexto da CEDH, "autoridades nacionais estão em melhor posição para tomar decisões sobre assuntos ambientais, os quais frequentemente têm aspectos sociais e técnicos difíceis. Portanto, ao chegar às suas decisões, concede às

60 CTIDH, OC-23/17, para. 59.

61 Embora não seja diretamente previsto pelo Protocolo de São Salvador, o Grupo de Trabalho foi criado por uma Resolução da Assembleia Geral da OEA (AG/RES. 2262 XXXVII-O/07) para "examinar os relatórios nacionais previstos no [artigo 19 do] Protocolo de São Salvador".

62 CTIDH, OC-23/17, para. 60. 
autoridades nacionais, em princípio, uma discricionariedade ampla...". 63 Pode-se questionar se a CtIDH vai seguir a mesma abordagem. É bem reconhecido que a CtIDH geralmente é menos deferente em relação aos Estados Partes. ${ }^{64}$ Este fato explica certa resistência por parte dos Estados partes às decisões da Corte sobre questões politicamente sensíveis, como leis de anistia. ${ }^{65}$ Uma situação parecida pode eventualmente ocorrer em relação a questões ambientais, especialmente à luz da aplicação da doutrina do controle de convencionalidade. ${ }^{66}$ Por fim, parece faltar um elemento fundamental e necessário em todo o raciocínio da Corte: orientação sobre como atingir um equilíbrio entre valores econômicos, sociais e ambientais.

\section{O DIREITO A UM MEIO AMBIENTE SAUDÁVEL NO CASO LHAKA HONHAT}

63 Do original: "national authorities are best placed to make decisions on environmental issues, which often have difficult social and technical aspects. Therefore in reaching its judgments, the Court affords the national authorities in principle a wide discretion....". Council of Europe Report, Council of Europe, Manual on Human Rights and the Environment (2nd ed., 2012), at 31. Veja, nesse sentido, CEDH. Powell and Rayner v. United Kingdom, No. 9310/81, Judgment Feburary 21,1990, para. 44. Veja também CEDH. Hatton and Others $v$. United Kingdom, No. 36022/97, Judgment, July 8, 2003, e CEDH. Hardy and Maile v. United Kingdom, No. 31965/07, Judgment, February 14, 2012. Por um lado, a Corte claramente reconhece, pela doutrina da margem de apreciação, certa liberdade de ação dos Estados. Por outro lado, como no caso Fadeyeva v. Rússia, a CEDH observou que "despite the wide margin of appreciation left to the respondent State, it has failed to strike a fair balance between the interests of the community and the applicant's effective enjoyment of her right to respect for her home and her private life. There has accordingly been a violation of Article 8 of the Convention." CEDH. Case of Fadeyeva v. Russia, No. 55723/00, Judgment of November 30, 2005, para. 134. Sobre essa questão, veja, no geral, PEDERSEN, O. W. European Environmental Human Rights and Environmental Rights: A Long Time Coming?, Georgetown International Environmental Law Review, Vol. 21, 2008, pp. 73-111. Northwestern Journal International Human, Vol. 11, 2012, p.28.

64 Veja, nesse sentido, CONTRETAS, P. National Discretion and International Deference in the Restriction of Human Rights: A Comparison Between the Jurisprudence of the European and the Inter-American Court of Human Rights.

65 CONTESSE, J. Resisting the Inter-American Human Rights System. Yale Journal of International Law, vol. 44, 2019, p. 179; HUNEEUS, A. V. Courts Resisting Courts: Lessons from the Inter-American Court's Struggle to Enforce Human Rights. Cornell International Law Journal, vol. 44, 2011, p. 493. Em relação às leis de anistia, veja BINDER, C. The Prohibition of Amnesties by the Inter-American Court of Human Rights. German Law Journal, Vol. 12, pp. 1203-1230; VEÇOSO, F. F. C. O criterio inter-americano sobre anistias: absolutismo de direitos humanos?. Revista Derecho del Estado, Vol. 35, 2015, p. 3; PEREZ-LEONACEVEDO, J. P. The control of the Inter-American Court of Human Rights over amnesty laws and other exemption measures: Legitimacy assessment. Leiden Journal of International Law, Vol. 33, 2020, pp.667-687. 66 Nesse sentido, veja DULITZKY, A. E. An Alternative Approach to the Conventionality Control Doctrine. AJIL Unbound, Vol. 109, 2015, p. 100. Veja também RAMOS, A. C. Control of Conventionality and the struggle to achieve a definitive interpretation of human rights: the Brazilian experience. Revista del Instituto Interamericano de Derechos Humanos, Vol. 64, 2016, pp. 11-32. 
No seu julgamento de 06 de fevereiro sobre o caso Comunidades Indígenas da Associação Lhaka Honhat (Nossa Terra) v. Argentina, a CtIDH encontrou ocasião para aplicar o raciocínio desenvolvido na Opinião Consultiva 23 pela primeira vez. Em resumo, o caso trata sobre 132 comunidades indígenas que instituíram queixas contra a Argentina devido à violação dos seus direitos de propriedade em várias ocasiões. Ademais, comunidades criollas causaram danos ambientais através da realização de atividades madeireiras nas propriedades indígenas e construíram cercas em partes do seu território. Os danos ambientais e a redução da biodiversidade foram apurados por meio de prova pericial, à qual a Corte atribuiu valor probatório significativo. ${ }^{67}$ Por estas razões, a Corte responsabilizou a Argentina, inter alia, por violar o direito a um meio ambiente saudável, o direito à alimentação adequada, e o direito à participação na vida e na identidade cultural. A Corte incluiu esses direitos (não reconhecidos expressamente na $\mathrm{CADH}$ ) sob o título de desenvolvimento progressivo estabelecido no artigo 26 da $\mathrm{CADH}$. É a primeira vez que a Corte declarou uma violação desses direitos per se de acordo com o artigo 26. No passado, a estratégia da Corte foi de se apoiar nos seus casos contenciosos anteriores para incluir os DESCA na lista de direitos litigáveis; na OC23/17, a Corte ancorou seu raciocínio para "se pronunciar sobre os direitos a um meio ambiente saudável, à alimentação adequada, à água e a participar na vida cultural a partir do artigo 26 da Convenção". ${ }^{68}$ A Corte responsabilizou a Argentina pela violação ao artigo 26 , dentre outros, e determinou a adoção de diferentes medidas de reparação.

Duas partes da decisão merecem atenção. A primeira se encontra no fato de que a judicialização do direito a um meio ambiente saudável por meio do artigo 26 causou uma divisão dentro da Corte. A segunda é o fato de que a Corte aplicou ao direito a

\footnotetext{
67 Sobre a questão, veja, de maneira geral, LIMA, L. C. The use of experts in environmental disputes before the International Court of Justice. In: LAVENA, V. (org.). Diritto Internazionale e Riforma: Atti del convegno della XVI Giornata Gentiliana. Macerata, 2017, pp. 31-56.

68 CTIDH, caso Lhaka Honhat, para. 201 e ss. Todas as traduções do espanhol para o português foram feitas pelo autor, uma vez que ainda não foi disponibilizada versão em português do julgamento.
} 
um meio ambiente saudável alguns dos padrões desenvolvidos na OC-23/17 em relação aos direitos à vida e à integridade pessoal.

A decisão relativa à judicialização dos DESCA através do artigo 26 ocorreu no contexto de uma Corte dividida. A divisão dos juízes no caso, a qual foi resolvida pelo voto de minerva raramente utilizado pelo Presidente da Corte, revela parte das tensões presentes na câmara de deliberação. Para a maioria, o princípio pro persona - cristalizado no artigo 29, o qual proíbe interpretações que suprimem ou restringem o gozo e exercício dos direitos reconhecidos na Convenção - justificou a expansão e judicialização dos DESCA. A CtIDH fez referência à sua própria jurisprudência, a qual reconheceu que "a Corte afirmou sua competência para determinar violações ao artigo 26 da Convenção Americana e indicou que o mesmo protege os direitos econômicos, sociais, culturais e ambientais derivados da Carta da Organização dos Estados Americanos, sendo pertinente para 0 seu entendimento as 'normas de interpretação' estabelecidas no artigo 29 da Convenção". 69 Em conformidade, "a Corte realiza uma interpretação que permite atualizar o significado dos direitos derivados da Carta que são reconhecidos no artigo 26 da Convenção". ${ }^{70}$ Parece que, além de uma interpretação teleológica, a Corte também empregou uma interpretação evolutiva ${ }^{71}$ da Convenção.

A maioria dos juízes também ofereceu motivos adicionais para incluir os DESCA no artigo 26 da Convenção. O juiz Mac-Gregor Poisot, por exemplo, parece também ter levado em consideração o fato de que a Argentina não contestou a competência da Corte para julgar sobre direitos ambientais (e outros) nos termos do artigo $26 .{ }^{72}$ Além disso, de acordo com ele, a falha em reconhecer a autonomia dos DESCA de acordo com o artigo 26 implicaria uma regressão contrária à jurisprudência da CIDH. Uma lógica similar parece estar presente no voto concorrente do juiz Pazmiño Freire, para o qual, em certas circunstâncias, "é necessário implementar uma

69 CTIDH, caso Lhaka Honhat, para. 195.

70 CTIDH, caso Lhaka Honhat, para. 199.

71 Sobre esse assunto, mas com foco especial em relação ao contexto europeu, veja BJORGE, E. The Evolutionary Interpretation of Treaties. Oxford, 2014.

72 CTIDH, caso Lhaka Honhat, Voto Concorrente do Juiz Ferrer Mac-Gregor Poisot, para. 6. 
hermenêutica expansiva da norma para garantir uma melhor proteção aos seres humanos". ${ }^{73}$

Alguns elementos e argumentos interessantes aparecem nas vozes dos três juízes dissidentes. O juiz Manrique ofereceu uma posição intermediária entre os defensores e os críticos da abordagem da Corte, visto que ele admitiu a possibilidade de uma violação aos DESCA, mas apenas em conjunto com outros direitos reconhecidos na Convenção. Para ele, "a Corte tem um dever convencional de fazer justiça em casos específicos dentro dos limites dados pelo direito dos tratados". ${ }^{74}$ Sua sugestão de proteger direitos ambientais em conexão com os outros direitos claramente estabelecidos pela CADH parece se assemelhar à posição adotada pela CEDH sobre o assunto. ${ }^{75}$

Os votos dissidentes mais aguilhoantes apontam para a fraqueza no raciocínio expansivo da Corte. O juiz Vio Grossi opta por um argumento baseado nos critérios de interpretação da Convenção de Viena sobre o Direito dos Tratados. Em uma exegese detalhada analisando o texto do artigo 26 , bem como outros documentos do corpus juris interamericano, Vio Grossi reitera seu argumento feito em relação à OC-23/17 de que as técnicas tradicionais de interpretação de tratados não permitem a inclusão dos DESCA como direitos justiciáveis. Para Vio Grossi, a interpretação utilizada pela Corte dá preferência ao método teleológico em detrimento de outros métodos em vista da indicação textual. $O$ juiz chileno parece sugerir que a interpretação da Corte é até mesmo contra legem na medida em que negligencia o texto, permitindo a justiciabilidade desses direitos, quando ele sugere que a Corte não "usa apropriadamente todos os meios de interpretação previstos na Convenção de Viena, [conduzindo] um resultado contrário á lógica e nunca desejado ou previsto na Convenção" ${ }^{76}$

73 CTIDH, caso Lhaka Honhat, Voto Concorrente do Juiz Patricio Pazmiño Freire, para. 11.

74 CTIDH, caso Lhaka Honhat, Voto Parcialmente Dissidente do Juiz Pérez Manrique, para. 16.

75 Apenas a título de exemplo, o direito a um meio ambiente saudável é reconhecido em conexão com o direito à vida nos casos Fadeyeva v. Russia e Öneryildiz v. Turquia, ou com o direito à propriedade privada nos casos López Ostra v. Espanha e Tatar v. Suécia.

76 CTIDH, caso Lhaka Honhat, Voto Parcialmente Dissidente do Juiz Vio Grossi, para. 88. 
O juiz Sierra Porto manifestou uma forte opinião sobre o assunto: de que a CIDH não tinha competência para lidar com os DESCA. ${ }^{77}$ Para o juiz colombiano, a Corte não possuía jurisdição expressa "nem pela Convenção Americana nem pelo artigo 19.6 do Protocolo (...) interpretado à luz dos artigos 30 e 31 da Convenção de Viena sobre o Direito dos Tratados". ${ }^{78} \mathrm{O}$ juiz Sierra Porto apoia essa posição no fato de que os Estados partes do Protocolo de São Salvador permitiram apenas que alguns direitos fossem litigados, não estando os direitos ambientais (inter alia) entre eles. Também se conclui que é problemático se referir a instrumentos internacionais de "soft law" por uma questão de conveniência. ${ }^{79}$

O criticismo presente nos votos dos três juízes conta algo e revela a fratura dentro da Corte. Porém, parece haver algo ausente nos votos dos juízes: o peso do precedente estabelecido pela OC-23/17. A Corte expressamente cita a OC-23/17 no caso Lhaka Honhat para apoiar a expansão dos direitos ambientais, o direito à alimentação, água, e participação e identidade cultural. Os juízes dissidentes negligenciam esse precedente em seus votos. Eles não abordam o fato de que a Corte já havia decidido sobre a justiciabilidade do direito a um meio ambiente saudável na OC-23/17 e que pode ser incongruente mudar esta posição em um caso contencioso. Os juízes dissidentes pareciam não estarem conscientes do fato de que não foi apenas no contexto de litigância, mas eminentemente através de jurisdição consultiva, que a principal ampliação dos DESCA ocorreu. Tal ampliação e aplicação contenciosa dos direitos desenvolvidos na esfera consultiva obviamente têm consequências e levantam questões.

Mas o impacto do caso Lhaka Honhat vai além da primeira aplicação do artigo 26 em relação a direitos ambientais, visto que também conecta as obrigações desenvolvidas na OC-23/17 com o direito a um meio ambiente saudável. Uma ilustração interessante é o fato de que, nesse caso, a Corte aplicou o dever de prevenir ("deber de prevención") como previamente enunciado na OC-23/17. ${ }^{80}$ Esse

77 CTIDH, caso Lhaka Honhat, Voto Parcialmente Dissidente do Juiz Sierra Porto, para. 6.

78 CTIDH, caso Lhaka Honhat, Voto Parcialmente Dissidente do Juiz Sierra Porto, para. 7. 79 CTIDH, caso Lhaka Honhat, Voto Parcialmente Dissidente do Juiz Sierra Porto, para. 7. 80 CTIDH, caso Lhaka Honhat, para. 208. 
dever de prevenir é particularmente espelhado nas reparações determinadas pela Corte. A Argentina foi condenada a "preparar um estudo estabelecendo ações a serem implementadas para a conservação de água e para evitar e remediar sua contaminação; garantir acesso permanente a água potável; prevenir a perda contínua ou diminuição de recursos florestais e buscar sua recuperação". ${ }^{81}$ Portanto, não é surpresa que a Corte aplique os padrões desenvolvidos anteriormente em relação à proteção do meio ambiente no que diz respeito ao direito à vida e à integridade pessoal. Contudo, a aplicação dos critérios materiais ao artigo 26 confirma a função quase legislativa da opinião consultiva da Corte sobre questões ambientais.

Certamente o caso Lhaka Honhat cristaliza um progresso importante na proteção de direitos ambientais no Sistema Interamericano. ${ }^{82}$ Não obstante, também revela que há problemas com a proteção ao direito a um meio ambiente saudável de acordo com o artigo 26 da Convenção. Pode-se ponderar se a Corte poderia ter chegado aos mesmos resultados no que se refere aos direitos já reconhecidos na CADH. O caso esclarece muitos pontos oriundos da especulação decorrente da

OC-23/17: Estados partes à CADH têm várias obrigações ambientais sob o artigo 26; são obrigados a agir em conformidade com essas obrigações e podem ser trazidos perante o Sistema Interamericano (Corte e Comissão) pela violação de tais obrigações; e a Corte pode determinar meios de reparação específicos em relação a direitos ambientais.

\section{CONCLUSÃO}

81 CTIDH, caso Lhaka Honhat, dispositif, item 12.

82 Há uma literatura crescente saudando o julgamento, por exemplo, TIGRE, M. A. Inter-American Court of Human Rights Recognizes the Right to a Healthy Environment. ASIL Insights, Vol. 24, Issue 14, June 022020 ; MOERLOOSE, S. DE.; IGNACIO DE CASAS, C. The Lhaka Honhat Case Of The Inter-American Court Of Human Rights: The Long-Awaited Granting Of 400,000 Hectares Under Communal Property Rights. EJILTalk, July 16, 2020; CABRERA, A.; CERQUEIRA, D.; HERENCIA, S. Comentarios a la sentencia de la Corte Interamericana sobre el Caso Lhaka Honhat vs. Argentina. Justicia en las Américas: Blog de la Fundación para el Debido Proceso, Abril 30, 2020; ANTONIAZZI, M. M.; NAVARRO, G. C. B. Tackling Inequality in Times of Pandemics: Right to Water in the Inter-American Court of Human Rights. In: Max Planck Institute for Comparative Public Law \& International Law (MPIL) Research Paper No. 2020-30, pp. 1-29. 
A interpretação ampla do artigo 26 da Convenção Americana, a incorporação de padrões internacionais para proteções ambientais vindo de regimes externos e a aplicação desses padrões em petições individuais contribuem para a percepção de que a CtIDH assumiu um papel proeminente como uma corte de direitos humanos com jurisdição ambiental. A "virada ambiental" da Corte inegavelmente terá um efeito tanto dentro quanto fora do sistema Interamericano. Há questionamentos que permanecem à espera de resposta.

O primeiro possível impacto da abordagem da Corte se dá no trabalho da Comissão Interamericana de Direitos Humanos. Se no passado a Comissão rejeitou como inadmissível uma reivindicação em nome de todos os cidadãos do Panamá para proteger uma reserva natural, pode-se esperar que a Comissão respeitará as decisões ambientais da Corte. ${ }^{83} \mathrm{O}$ segundo impacto esperado está dentro dos ordenamentos jurídicos domésticos por meio da doutrina do controle de convencionalidade, a qual requer que juízes nacionais apliquem os padrões interamericanos na aplicação direta da CADH. Os Estados podem aderir voluntariamente aos padrões interamericanos e promover um "esverdeamento" 84 do seu direito doméstico.

Um conjunto de questões em desdobramento diz respeito ao conteúdo normativo do artigo 26 da CADH. Pode-se perguntar se, à luz da nova interpretação da Corte, todos os direitos consagrados no Protocolo de São Salvador podem ser autonomamente litigados sob a rubrica do artigo 26. O fato de que outros direitos não mencionados diretamente pela jurisprudência anterior e que foram aplicados no caso Lhaka Honhat por meio do artigo 26 parece sugerir uma resposta positiva. Se este entendimento prevalecer, a limitação à jurisdição da Corte decorrente do artigo 19.6 do Protocolo de São Salvador se tornará letra morta.

O terceiro conjunto de questões diz respeito às reações à posição expansiva da Corte. Estados americanos e outros atores sociais interamericanos podem mostrar

83 COMISSÃO INTERAMERICANA DE DIREITOS HUMANOS. Metropolitan Nature Reserve v. Panama, Case 11.533, Report No. 88/03, 22 October 2003, para. 34.

84 SANDS, P. The Greening of International Law: Emerging Principles and Rules. Indiana Journal of Global Studies, Volume 1, 1994, pp. 293-323. 
reações diferentes em relação à justiciabilidade direta de direitos ambientais e outros direitos sociais. Tais reações podem ter um impacto particular na influência e na autoridade da Corte, bem como sobre a eficácia de suas decisões. Resta saber se os Estados vão ser mais resistentes a decisões baseadas na interpretação ampliada do artigo 26. O movimento ousado de reivindicar competências ambientais tem um preço. No contexto de resistência, reação e contestação, ${ }^{85}$ as reações dos Estados a essa abordagem ambiental ainda estão para se descortinarem. Em abril de 2019, cinco Estados divulgaram uma declaração comum sobre o sistema americano ${ }^{86}$ argumentando a favor de ser dada mais deferência ao ponto de vista dos Estados. Embora a declaração tenha sido feita antes do caso Lhaka Honhat, o documento finalizou com uma defesa da "implementação estrita das fontes de direito internacional" e argumentou a implementação da doutrina da margem de apreciação pela Corte. Esse documento é indicativo das futuras tensões que a abordagem da Corte pode originar.

Pelo mesmo motivo, o desenvolvimento de certos direitos e obrigações através da função consultiva com a aplicação posterior na jurisprudência levanta fortes questões sobre elaboração de leis e participação judiciária, um argumento desenvolvido pelo juiz Sierra Porto. Ao permitir que os DESCA sejam litigados por meio do artigo 26, a CtIDH não está apenas oferecendo uma contribuição substancial à sua jurisprudência, mas também está adicionando novos contornos àqueles direitos e sua implementação progressiva. Futuros litígios ambientais (e de direitos econômicos, sociais e culturais) perante a CIDH podem revelar quais são, se existirem, os limites da interpretação do artigo 26.

85 Veja, nesse sentido, MADSEN, M. R.; CEBULAK, P.; WIEBUSCH, M. Backlash against international courts: explaining the forms and patterns of resistance to international courts. International Journal of Law in Context, Vol. 14, 2018, pp. 197-2020; e Huneuus, A. Courts Resisting Courts: Lessons from the InterAmerican Court's Struggle to Enforce Human Rights. Cornell International Law Journal, Vol. 44, 2011, pp. 493-533.

86 Declaração Comum sobre o Sistema Interamericano de Direitos Humanos feita pelos governos argentino, brasileiro, chileno, colombiano e paraguaio. Disponível em: <https://www.mre.gov.py/index.php/noticias-deembajadas-y-consulados/gobiernos-de-argentina-brasil-chile-colombia-y-paraguay-se-manifiestan-sobre-elsistema-interamericano-de-derechos-humanos>. 


\section{REFERÊNCIAS}

ABELLO-GALVIS, R.; AREVALO-RAMIREZ, W. INTER-AMERICAN COURT OF HUMAN RIGHTS ADVISORY OPINION OC-23/17: JURISDICTIONAL, PROCEDURAL AND SUBSTANTIVE IMPLICATIONS OF HUMAN RIGHTS DUTIES IN THE CONTEXT OF ENVIRONMENTAL PROTECTION. REVIEW of European, Comparative and INTERnational ENVIRONMENTAL LaW, Vol. 28, 2019, PP. 217-222.

ANTKOWIAK, T. A "Dignified Life" and the Resurgence of Social Rights. Journal of Human Rights, Vol. 18, 2020, pp. 1-51.

ANTONIAZZI, M. M.; NAVARRO, G. C. B. Tackling Inequality in Times of Pandemics: Right to Water in the Inter-American Court of Human Rights. In: Max Planck Institute for Comparative Public Law \& International Law (MPIL) Research Paper No. 2020-30, pp. 1-29.

ASTA, G. La funzione consultiva delle corti regionali dei diritti umani. Napoli, 2019.

BAILLIET, C. The strategic prudence of The Inter-American Court of Human Rights: rejection of requests for an advisory opinion. Revista de Direito Internacional, Vol. 15, 2018, p. 254.

BESSON, S. The Extraterritoriality of the European Convention on Human Rights: Why Human Rights Depend on Jurisdiction and What Jurisdiction Amounts to. Leiden Journal of International Law, Vol. 25, 2012, pp. 857-884.

BINDER, C. The Prohibition of Amnesties by the Inter-American Court of Human Rights. German Law Journal, Vol. 12, pp. 1203-1230.

BJORGE, E. The Evolutionary Interpretation of Treaties. Oxford, 2014.

BOYLE, A. Human Rights and the Environment: Where Next?. In: BOER, B. (ED.), Environmental Law Dimensions of Human Rights, Oxford, 2015, pp. 201-239.

BRUNEÉ, J. The Sources of International Environmental Law: Interactional Law. In: Besson, S; D'AsPREMONT, J. (eds.). The Oxford Handbook on Sources of International Law. Oxford, 2017, pp. 960-983. 
BUERGENTHAL, T. The Advisory Practice of the Inter-American Human Rights Court, American Journal of International Law. Vol. 79, 1985, pp. 1-27.

BURGORGUE-LARSEN, L. Economic and social rights. In: BURGORGUELARSEN, L; ÚBEDA DE TORRES, A. The Inter-American Court of Human Rights: Case Law and Commentary. Oxford, 2011, pp. 613-641.

BURGORGUE-LARSEN, L. "Decompartmentalization": The key technique for interpreting regional human rights treaties. International Journal of Constitutional Law, Vol. 16, 2018, p. 187-213.

CABRERA, A.; CERQUEIRA, D.; HERENCIA, S. Comentarios a la sentencia de la Corte Interamericana sobre el Caso Lhaka Honhat vs. Argentina. Justicia en las Américas: Blog de la Fundación para el Debido Proceso, Abril 30, 2020.

CAMPILLAY, E. A. G. Derecho a vivir en un medio libre de contaminación o medio ambiente sano como Derecho Humano ante la jurisprudencia y Comisión de la Corte Interaméricana de Derechos Humanos. Cuadernos de Extensión Jurídica, Vol. 28, 2016, pp. 99-119.

CANÇADO TRINDADE, A. A. A justiciabilidade dos direitos económicos, sociais e culturais no plano internacional. In: Presente y futuro de los Derechos Humanos. Ensayos en honor a Fernando Volio Jiménez, Instituto Interamericano de Derechos Humanos, San José, 1998.

CANÇADO TRINDADE, A. A. Principle 15: Precaution. In: VIÑUALES, J. (Ed.) Rio declaration on environment and development: a commentary, 2015, pp. 403-428.

COMISSÃO INTERAMERICANA DE DIREITOS HUMANOS. Case of Coard et al. $v$. United States. Merits Report No. 109/99 of September 29, 1999, para. 37.

COMISSÃO INTERAMERICANA DE DIREITOS HUMANOS. Metropolitan Nature Reserve v. Panama, Case 11.533, Report No. 88/03, 22 October 2003, para. 34.

COMISSÃO INTERAMERICANA DE DIREITOS HUMANOS. Franklin Guillermo Aisalla Molina (Ecuador v. Colombia). Admissibility Report No. 112/10 of October 21, 2011, para. 91. 
CONSELHO DE DIREITOS HUMANOS. Mapping report of the Independent Expert on the issue of human rights obligations relating to the enjoyment of a safe, clean, healthy and sustainable environment, John H. Knox, 30 December 2013, UN Doc. $\mathrm{A} / \mathrm{HRC} / 25 / 53$.

CONSELHO DE DIREITOS HUMANOS. Report of the Special Rapporteur on the issue of human rights obligations relating to the enjoyment of a safe, clean, healthy and sustainable environment, John H. Knox, 19 July 2018, UN Doc A/73/188, para. 53.

CONTESSE, J. Resisting the Inter-American Human Rights System. Yale Journal of International Law, Vol. 44, 2019, p. 179.

CONTRETAS, P. National Discretion and International Deference in the Restriction of Human Rights: A Comparison Between the Jurisprudence of the European and the Inter-American Court of Human Rights.

CORTE AFRICANA DE DIREITOS HUMANOS E DOS POVOS. African Commission on Human and People's Rights v. Republic of Kenya. No. 006/2012, Judgment, May 26, 2017.

CORTE EUROPEIA DE DIREITOS HUMANOS. Powell and Rayner v. United Kingdom, No. 9310/81, Judgment Feburary 21,1990, para. 44.

CORTE EUROPEIA DE DIREITOS HUMANOS. Hatton and Others $v$. United Kingdom, No. 36022/97, Judgment, July 8, 2003.

CORTE EUROPEIA DE DIREITOS HUMANOS. Case of Fadeyeva v. Russia, No. 55723/00, Judgment of November 30, 2005, para. 134.

CORTE EUROPEIA DE DIREITOS HUMANOS. Hardy and Maile v. United Kingdom, No. 31965/07, Judgment, February 14, 2012.

CORTE INTERAMERICANA DE DIREITOS HUMANOS. Enforceability of the Right of Reply or Rectification (Arts. 14.1, 1.1 and 2 American Convention on Human Rights), Advisory Opinion OC-07/86 of 29 August, 1986. Series A No. 7, para. 12. 
CORTE INTERAMERICANA DE DIREITOS HUMANOS. The Right to Information on Consular Assistance in the Framework of the Guarantees of the due Process of Law, Advisory Opinion OC-16/99 of 01 October, 1999. Series A No. 16, para. 1999. CORTE INTERAMERICANA DE DIREITOS HUMANOS. Case of Salvador Chiriboga v. Ecuador, Preliminary Objections and Merits, Judgment of May 6, 2008 Series C No. 179.

CORTE INTERAMERICANA DE DIREITOS HUMANOS. Case of Kichwa Indigenous People of Sarayaku v. Ecuador, Merits and Reparations, Judgment of June 27, 2012. Series C No. 245.

CORTE INTERAMERICANA DE DIREITOS HUMANOS. Case of the Massacres of El Mozote and surrounding areas v. El Salvador. Merits, Reparations and Costs, Judgment of October 25, 2012. Series C No. 252, para. 141.

CORTE INTERAMERICANA DE DIREITOS HUMANOS. Case of the Santo Domingo Massacre v. Colombia. Preliminary Objections, Merits and Reparations, Judgment of November 30, 2012. Series No. 259, para. 23

CORTE INTERAMERICANA DE DIREITOS HUMANOS. Case of the Kaliña and Lokono Peoples v. Suriname, Merits, Reparations and Costs, Judgment of November 25, 2015. Series C No. 309.

CORTE INTERAMERICANA DE DIREITOS HUMANOS. Case Lagos del Campo v. Peru, Preliminary Objections, Merits, Reparations and Costs, Judgment of August 31, 2017. Series C No. 340.

CORTE INTERAMERICANA DE DIREITOS HUMANOS. The Environment and Human Rights (State obligations in relation to the environment in the context of the protection and guarantee of the rights to life and to personal integrity - interpretation and scope of Articles 4(1) and 5(1) of the American Convention on Human Rights), Advisory Opinion OC-23/17 of 15 November, 2017. Series A No. 23.

CORTE INTERAMERICANA DE DIREITOS HUMANOS. Caso Poblete Vilches $y$ otros v. Chile. Merits, Reparations and Costs, Judgment of 8 March 2018, Series C No. 349 , para. 110. 
CORTE INTERAMERICANA DE DIREITOS HUMANOS. Case of Cuscul Pivaral et al. v. Guatemala, Preliminary Objection, Merits, Reparations and Costs, Judgment of August 23, 2018. Series C No. 359.

CORTE INTERAMERICANA DE DIREITOS HUMANOS. Case of Muelle Flores v. Peru, Preliminary Objections, Merits, Reparations and Costs, Judgment of March 6, 2019. Series C No. 375.

CORTE INTERAMERICANA DE DIREITOS HUMANOS. Caso Comunidades Indígenas Miembros de la Asociación Lhaka Honhat (Nuestra Tierra) v. Argentina. Fondo, Reparaciones y Costas, Sentencia de 6 de febrero de 2020.

CORTE INTERNACIONAL DE JUSTIÇA, Alleged Violations of Sovereign Rights and Maritime Spaces in the Caribbean Sea (Nicaragua v. Colombia).

COURTIS, C. Artículo 26 - Desarrollo Progresivo. In: STEINER, C.; URIBE, P. (eds.). Convención Americana sobre Derechos Humanos Comentada..Mexico, 2014, p. 654.

DE PAZ GONZÁLEZ, I. The Social Rights Jurisprudence in the Inter-American Court of Human Rights: Shadow and Light in International Human Rights. Cheltenhan, 2018.

DULITZKY, A. E. An Alternative Approach to the Conventionality Control Doctrine. AJIL Unbound, Vol. 109, 2015, p. 100.

ESTUPIÑAN SILVA, R. Primera opinión interamericana sobre medio ambiente: ¿derecho exigible o decisión ultra vires?. Criterio Jurídico Garantista, Vol. 11, pp. 61-80.

FERIA-TINTA, M.; MILNES, S. C. International Environmental Law for the 21st Century: The Constitutionalization of the Right to a Healthy Environment in the InterAmerican Court of Human Rights Advisory Opinion 23. Anuario Colombiano de Derecho Internacional, Vol. 12, 2019, pp. 43-84.

FOSTER, C. E. Science and the Precautionary Principle in International Courts and Tribunals. Cambridge, 2011, p. 18. 
FRANCIONI, F. International Human Rights in an Environmental Horizon. European Journal of International Law, Vol. 21, No. 1, 2019, pp. 41-55.

GAMBOA, J. G. Medio Ambiente frente a la Corte Interamericana de Derechos Humanos: una ventana de protección. In: CANÇADO TRINDADE, A. A.; BARROS LEAL, C. (EDS). Derechos Humanos y Medio Ambiente. Fortaleza, 2017, pp. 103-144.

GIANNINO, D. The Ground-Breaking Advisory Opinion OC-23/17 of the InterAmerican Court of Human Rights: Healthy Environment and Human Rights. Blog of the International Journal of Constitutional Law, 2018.

HUNEEUS, A. V. Courts Resisting Courts: Lessons from the Inter-American Court's Struggle to Enforce Human Rights. Cornell International Law Journal, vol. 44, 2011, p. 493.

KOTZÉ, L. J.; DU PLESSIS, A. A. The African Charter on Human and Peoples' Rights and Environmental Rights Standards. In: Turner, S. et al (eds). Environmental Rights: The Development of Standards, Cambridge, 2019, 93-115.

LIMA, L. C. The use of experts in environmental disputes before the International Court of Justice. In: LAVENA, V. (org.). Diritto Internazionale e Riforma: Atti del convegno della XVI Giornata Gentiliana. Macerata, 2017, pp. 31-56.

LIXINSKI, L. Treaty Interpretation by the Inter-American Court of Human Rights: Expansionism at the Service of the Unity of International Law. European Journal of International Law, Vol. 21, 2010, p. 604.

LÓPEZ ZAMORA, L. A. El enfoque extractivo del derecho ambiental y los desafíos del concepto de "pueblos indígenas". Anuario Mexicano de Derecho Internacional, Vol. XIX, 2014, pp. 301-345.

MADSEN, M. R.; CEBULAK, P.; WIEBUSCH, M. Backlash against international courts: explaining the forms and patterns of resistance to international courts. International Journal of Law in Context, Vol. 14, 2018, pp. 197-2020

MILANOVIC, M. Extraterritorial Application of Human Rights Treaties: Law, Principles and Policy, Oxford, 2011. 
MOERLOOSE, S. DE.; IGNACIO DE CASAS, C. The Lhaka Honhat Case Of The Inter-American Court Of Human Rights: The Long-Awaited Granting Of 400,000 Hectares Under Communal Property Rights. EJILTalk, July 16, 2020.

PAPANTONIOU, A. Advisory Opinion on the Environment and Human Rights. American Journal of International Law, Vol. 112, 2018, pp. 460-466.

PAVONI. R. Environmental Jurisprudence of the European and Inter-American Courts of Human Rights. In: BOER, B. (ED.), Environmental Law Dimensions of Human Rights. Oxford, 2015.

PEDERSEN, O. W. European Environmental Human Rights and Environmental Rights: A Long Time Coming?, Georgetown International Environmental Law Review, Vol. 21, 2008, pp. 73-111. Northwestern Journal International Human, Vol. 11,2012, p.28.

PEDERSEN, O. W. The European Court of Human Rights and International Environmental Law. In: KNOX, J. H.; PEJAN, R. (eds.) The Human Right to a Healthy Environment. Cambridge, 2018, pp. 97-121.

PEREZ-LEON-ACEVEDO, J. P. The control of the Inter-American Court of Human Rights over amnesty laws and other exemption measures: Legitimacy assessment. Leiden Journal of International Law, Vol. 33, 2020, pp.667-687.

RAMOS, A. C. Control of Conventionality and the struggle to achieve a definitive interpretation of human rights: the Brazilian experience. Revista del Instituto Interamericano de Derechos Humanos, Vol. 64, 2016, pp. 11-32.

ROA, J. E. La función consultiva de la Corte Interamericana de Derechos Humanos. Bogotá, 2015.

RODRIGUEZ, G. Articulo 29 - Normas de Interpretación. In: STEINER, C.; URIBE, P. (eds). Convención Americana sobre Derechos Humanos Comentada. Mexico, 2014, pp.706-714.

RUIZ-CHIRIBOGA, O. R. The American Convention and the Protocol of San Salvador: Two Intertwined Treaties: Non-Enforceability of Economic, Social and 
Cultural Rights in the Inter-American System. Netherlands Quarterly of Human Rights, Vol. 31, 2, 2017, pp. 159-186.

SANDS, P. The Greening of International Law: Emerging Principles and Rules. Indiana Journal of Global Studies, Volume 1, 1994, pp. 293-323.

SCHMID, J. C. Advisory Opinions on Human Rights: Moving Beyond a Pyrrhic Victory, Duke Journal of Comparative \& International Law. Vol. 16, 2006, pp. 415456

SHELTON, D. Derechos ambientales y obligaciones en el sistema interamericano de derechos humanos. Anuario de Derechos Humanos, №. 6, 2010, pp. 111-127. SCOVAZZI, T. L'interpretazione e l'applicazione "ambientalista" della Convenzione europea dei diritti umani, con particolare riguardo al caso "Urgenda". Rivista Giuridica dell'Ambiente, 2019, pp. 619-633.

TIGRE, M. A. Inter-American Court of Human Rights Recognizes the Right to a Healthy Environment. ASIL Insights, Vol. 24, Issue 14, June 022020.

TREVES, T. Environmental Impact Assessment and the Precautionary Approach: Why Are International Courts and Tribunals Reluctant to Consider Them as General Principles of Law? In: Andenas, M.; Fitzmaurice, M.; TANZI, A.; Wouters, J. (eds.). General Principles and the Coherence of International Law, Leiden, 2019, pp. 379388.

VEÇOSO, F. F. C. O criterio inter-americano sobre anistias: absolutismo de direitos humanos?. Revista Derecho del Estado, Vol. 35, 2015, p. 3.

VEGA-BARBOSA, G.; ABOAGYE, L. A Commentary on the Advisory Opinion of the Inter-American Court of Human Rights on the Environment and Human Rights. DPCE Online, Vol. 34 No. 1, 2018, pp. 291-297.

VON BOGDANDY, A.; URUEÑA, R. International Transformative Constitutionalism in Latin America. American Journal of International Law, Vol. 114, 2020, pp. 403442. 